\title{
Moves and steps analysis of the message from CEO in in-flight magazines
}

\author{
Narudol Semchuchot (PhD Candidate) ${ }^{a}$, Wannana Soontornnaruerangsee (PhD) ${ }^{b}$ \\ aDepartment of Foreign Languages, Kasetsart University, Bangkok, Thailand 66-25795566, \\ nspin84@gmail.com \\ ${ }^{b}$ Department of Foreign Languages, Kasetsart University, Bangkok, Thailand
}

\begin{abstract}
This study was aimed to investigate English language moves and steps of thirty purposively selected messages from the CEO in in-flight magazines from five airlines (British Midland Airlines, Gulf Air, Jetstar Airways, Thai Airways International and United Airlines) by adopting Bhatia's (2014) sales promotion letter model. The findings revealed that the three most frequently found moves were considered obligatory basing on Kanoksilapatham's (2007) proposition. The three moves were Move 7 'Ending politely', Move 1 'Establishing Credentials' and Move 2 'Introduction of the offer', respectively. Moreover, it was also found that the most prominent organization of moves found in the corpus was Move 1 followed by Move 2 and Move 7. Move 2, which comprised three steps, 'Offering the product or services', 'Essential detailing of the offer' and 'Indicating value of the offer', was found to be the most repetitive. The findings of the study could be a guideline for international communication in English, English writing pedagogy as well as business communication.
\end{abstract}

Keywords: moves and steps analysis; message from CEO; in-flight magazine; international communication

\section{Introduction}

It is pointed out in studies of global English that apart from the English-speaking nations' political power and influence, the expansion of English use is attained by the superiority in various fields of commerce (Kachru, 1985; Quirk, 1985). Like other international businesses, the communication tool in the travel industry is the English language. Blue and Harun (2003) state that international travel is a rapidly growing, activity entailing cross-cultural communication between hosts and guests from different linguistic backgrounds. English is therefore considered the global language for its wide use in communication among people, including between business sectors and their customers.
One of the fastest growing businesses around the world is the airline industry. English is the tool in this mass communication; a type of communication which not only contributes to promoting airline companies' image, but also contributes to advertising products and services to prospective customers from all around the world (Roberts, 1993). Most commercial airlines provide in-flight magazines for their passengers as an entertainment amenity. Thanasupsin, Chaichana and Pliankarom (2010) indicate that in-flight magazine is one factor affecting Thai domestic air travellers' decision to fly Thai Airways International, which offers in-flight magazines; low-cost airlines do not offer inflight magazines. 
A large number of airlines' in-flight magazines contain a Message from the airline CEO (Chief Executive Officer) which tends to appear as the first editorial content or feature article (non-advertisement content). Oliver (2000) states that the message from the CEO appearing at the front part of business companies' annual reports is an important corporate communication strategy and is also perceived as a way for the organisation to personify its culture and personality. As the highest authority in an airline company, CEOs and their messages speak to multinational customers on behalf of the whole company.

The distribution of an airline's in-flight magazine of only one airline could reach a large number of readers per day. On a wide-bodied aircraft such as a Boeing 747, there would be approximately 400 in-flight magazines available, one at every seat, for all passengers on board. A major airline may have the capacity of serving thousands of passengers daily. The International Air Transportation Association (IATA) airline members alone consist of more than 150 airlines worldwide. Apart from the large distribution, inflights magazines appear to have high impact on the readers. The United States of America has the largest airline industry in the world. According to Arbitron Inc. (2006), seventy percent of the subjects who are in-flight magazine readers have acted upon information they read in the United Airlines and US airways airlines' magazines. This shows that inflight magazines have a strong impact towards passengers who are customers as well as message receivers; therefore, content in in-flight magazines is important in representing and selling airlines' image and products. The study by Arbitron (2006) shows that eighty percent of the surveyed readers have followed instructions and information provided in the in-flight magazines they have read.

Despite the highest authority airline companies' CEOs hold, the large number of potential readers and the influence of in-flight magazines could have upon air travellers, studies which focus directly on the Message from the $\mathrm{CEO}$ in in-flight magazines are rare; therefore, it is interesting to study how the English language is used in Message from CEOs in in-flight magazines. One salient approach in language analysis is genre analysis. Swales (1990) discusses genre analysis as an approach to study language in use aiming to understand spoken or written text as it is. In order to clarify or propose a genre of a certain type of text, language moves should be investigated because moves are discoursal units which communicate actual communicative purposes of texts. Genre in this study refers to the communicative event in the context of in-flight magazines in which the airline $\mathrm{CEO}$ communicates purposes in the English language to multi-national air travellers. One of the most recognised frameworks for English language in business context is Bhatia's (2014) 'promotional genre'. In order to serve all of the communicative purposes in sales promotion letters, Bhatia (2014) assigns the following moves and steps names; 
Table 1. Moves and steps of sales promotion letters by Bhatia (2014)

Move 1: Establishing credentials

Move 2: Introduction of the offer

Step 1: Offering the product or services

Step 2: Essential detailing of the offer

Step 3: Indicating value of the offer

Move 3: Offering incentives

Move 4: Enclosing documents

Move 5: Soliciting responses

Move 6: Using pressure tactics

Move 7: Ending politely

Rhodes (1999) investigates the overall purposes of in-flight magazines from twentythree airlines. She points out that in-flight magazines attempt to create a new editorial market through content. Forty-four percent of the editorial content is in the entertainment and travel categories. Based on her findings, four objectives of an airline magazine are identified. These objectives are 1) promoting the airline's image, 2) providing passengers with a service, 3) promoting destinations covered by the carrier, and 4) making money. The selected messages from the $\mathrm{CEO}$ in in-flight magazines in the present study, as part of an in-flight magazine, are categorised in the promotional genre based on Rhodes' (1999) findings, which are in accordance with Bhatia's (2014) model of moves and steps of sales promotion letters.

In this study, moves and steps of the English language used in the Message from the $\mathrm{CEO}$ in selected in-flight magazines from airlines of different aviation industry regions were investigated by adopting Bhatia' s (2014) model of move analysis. The results may provide an example and a guideline for in-flight magazines and related writings for international communication.

\section{Method}

\subsection{Sampling and Data Collection}

In order to represent a wide range of variety, in-flight magazines containing a Message from the $\mathrm{CEO}$ or its equivalence were purposively selected from five airlines of different regions of the world which were Europe, Middle-East, Australia, South East Asia and North America. The names of the selected in-flight magazines and the airlines were 1) Voyager of British Midland Airlines or BD from Europe, 2) Gulf Lite of Gulf Air or GF from the Middle East, 3) Jetstar of Jetstar Airways or JQ from Australia, 4) Sawasdee of Thai Airways International or TG from South East Asia and 5) Hemisphere of United Airlines or UA from North America. These five airlines were selected based on the following criteria:

1. Each of them was an international commercial airline

2. They offered in-flight magazines

3. In-flight magazines contained a message from the CEO or its equivalence (for Thai Airways, it was titled 'Message from the President'; nonetheless, the president was the highest rank in the company)

4. The Messages from the CEO were accessible either online or by hard copy

The following table, table 2, presents the data collection process of this study. 


Purposively selected five airlines of different aviation regions for data collection.
Compiled six most recent issues of Message from the CEO in in-flight magazines from the
purposively selected five airlines
A total of thirty messages from CEO were collected
The thirty collected messages from the CEO in in-flight magazines were copied, processed and
numbered
The analysis of moves and steps by identifying communicative purposes of the collected
data began

The selected data in this study was collected either online or by obtaining hard copy. For this study, the Message from the CEO of all airlines was available and was collected online

$$
\text { except }
$$

Thai

Airways' Sawasdee magazine whose hard

copies were collected as they were not available online. For accuracy of the data, the photocopied data was scanned and saved while the online version was also saved. Then the written messages were processed onto computer software and compiled as the data of this study. Next, the thirty collected messages from the $\mathrm{CEO}$ were arranged alphabetically by airlines' names and chronologically by the month each in-flight magazine was distributed. Then, the thirty messages were numbered; therefore, the message from the CEO in Voyager of British Midland Airlines from January was number one, and respectively, the message from the $\mathrm{CEO}$ in Hemisphere of United Airlines from June was number thirty. The thirty messages from $\mathrm{CEO}$ were analysed in order to identify the moves and steps as well as the organization of the moves and steps found in the selected Messages from the CEO.

\subsection{Data Analysis Procedures}

The first stage of the analysis concerned a qualitative procedure as the investigation of communicative purposes was implemented in order to identify moves and steps of each discoursal unit of the collected data before assigning a move name or a move and step name to each discoursal unit. The second stage involved a quantitative procedure when the frequency of each move and step was counted and accumulated for presentation by percentage. The organisations of moves and steps were also counted.

Firstly, each of the collected and numbered Messages from the CEO in in-flight magazines was read carefully by the researcher starting from Message from the CEO number one to number thirty accordingly. The researcher read the collected data carefully in order to investigate the communicative purpose of each discoursal unit based on Bhatia's (2014) model. A discoursal unit could be a paragraph, a sentence or a phrase. The researcher of this study was a graduate student majoring in English for Specific Purposes who worked as a flight attendant at the largest commercial airline in Thailand for nine years. Before the actual analysis of the collected data, the researcher practiced analysing moves and steps of the early issues of the selected in-flight magazines. A total of fifteen messages from the CEO from October to December 2011 were analysed in the practice. The practice of moves and steps analysis was under the supervision of a lecturer who taught English majored undergraduate and graduate students at a university in Thailand. After communicative purposes were identified, a move name was 
assigned to each discoursal unit in accordance with its function. The names of the moves were assigned according to Bhatia's (2014) moves and steps model.

While the other moves did not have any step, Move 2, 'Introduction of the offer', consisted of three steps, namely 1) offering the product or services, 2) essential detailing of the offer and 3) indicating value of the offer (Bhatia, 2014). A step name was assigned to each discoursal unit under move 2 depending on its function.

Any doubts concerning the communicative purposes of any discoursal unit, consultations with the selected specialists were sought. One-third of the analysis done by the researcher was cross-checked for accuracy by two selected specialists. The moves or steps not agreed by a specialist were discussed until agreement was reached. When at least eighty percent of the data analysed were agreed by both specialists, the moves and steps analysed and assigned by the researcher were finalised.

In the second stage, frequencies of moves and steps were counted and presented in percentage in tabulated form. The percentage of each move determined whether a move was obligatory. If a move occurred more than sixty percent, it was labelled as an 'obligatory move' based on Kanoksilapatham's (2007) proposition. A move found less than sixty percent was labelled as 'optional'. The obligatory moves found in this study may represent the style of writing based on the communicative purposes of the collected Message from the CEO in in-flight magazines. The organisations of moves and steps were also presented and discussed accordingly.

\subsection{Validity and reliability}

To assure the accuracy of the analysis, two specialists were sought for data analysis verification. One specialist was a Thai person who has worked in the airline industry for fifteen years. The specialist held a doctoral degree in English as International Language. The specialist taught graduate students and advised a number of theses for Master of Arts students in English language at a university in Thailand. The other specialist was a native English speaker who taught English language to undergraduate and graduate students at a university in Thailand. The specialist had experience in validating data in genre analysis of a number of theses for Master of Arts students in English for Specific Purposes.

One third of the data analysis, which comprised ten messages from the CEO in the selected in-flight magazines, was validated by the two specialists. In case a move or a step was not agreed by any of the two specialists, the move or step was discussed between the researcher and the specialists for an agreement of the best identification of the move or step. A move or step assigned to each discoursal unit was finalised and counted for frequencies only when at least eighty percent of the analysis was agreed to by both specialists.

\section{Results}

This section comprises two parts of the study results. The first part presents the frequency of moves and steps found in the selected Message from the $\mathrm{CEO}$ in in-flight magazines. Obligatory moves and organizations of moves and steps are presented in the second part of this section.

\subsection{Moves and Steps Frequencies}

This part of the section presents the frequency of moves and steps found in the selected Message from the CEO in in-flight magazines. The investigation of moves and steps adopted Bhatia's (2014) move and steps model for sales promotion letter. Only discoursal units whose communicative purpose matches one of the adopted moves were presented whereas discoursal units which did not match any of the adopted moves were disregarded. The 
results are illustrated in the table below followed

by a description of the findings.

Table 3. Frequencies of occurrence of moves and steps found in the thirty selected messages from CEO in in-flight magazines

\begin{tabular}{|c|c|c|}
\hline $\begin{array}{l}\text { Move or } \\
\text { Move and Step }\end{array}$ & Move or Move and Step Names & Number of Occurrence \\
\hline
\end{tabular}

$\begin{array}{llll}\text { Move 1 } & \text { Establishing credentials } & 26 & 86.66 \\ \begin{array}{ll}\text { Move 2 } \\ \text { Step 1 }\end{array} & \begin{array}{l}\text { Introduction of the offer } \\ \text { Offering the product or services }\end{array} & 22 & 73.33 \\ \begin{array}{l}\text { Move 2 } \\ \text { Step 2 }\end{array} & \begin{array}{l}\text { Introduction of the offer } \\ \text { Essential detailing of the offer }\end{array} & 14 & 43.66 \\ \begin{array}{l}\text { Move 2 } \\ \text { Step 3 }\end{array} & \begin{array}{l}\text { Introduction of the offer } \\ \text { Indicating value of the offer }\end{array} & 18 & 60 \\ \text { Move 3 } & \text { Offering incentives } & 2 & 6.66 \\ \text { Move 4 } & \text { Enclosing documents } & 9 & 30 \\ \text { Move 5 } & \text { Soliciting responses } & 6 & 20 \\ \text { Move 6: } & \text { Using pressure tactics } & 4 & 13.33 \\ \text { Move 7 } & \text { Ending politely } & 28 & 93.33 \\ \text { TOTAL } & & & 100\end{array}$

Considering the percentage of occurrences from the findings as shown in table 3 , Move 7 is the most frequently found move at $93.33 \%$. The second most frequent move is Move 1 'Establishing credentials' which is found $86.66 \%$. Third is Move 2, which comprises three steps. Move 2 Step 1 occurred 73.335, while Move 2 Step and Move 2 Step 3 occurred
$43.66 \%$ and $60 \%$ respectively. The total of all three steps of Move 2 occur 73.33\%.

Move 3 'Offering incentives' occurs the least at 6.66\%. Move 4 'Enclosing documents', Move 5 'Soliciting responses' and Move 6 'Using pressure tactics' occurred $30 \%, 20 \%$ and $13.33 \%$ respectively. 
Table 4. Obligatory and optional moves of message from the CEO in in-flight magazines

\begin{tabular}{lll}
\hline Percentage $\%$ & $\begin{array}{l}\text { Scale of Move Frequency } \\
\text { (from most to least frequent) }\end{array}$ & $\begin{array}{l}\text { Obligatory or } \\
\text { Optional Move }\end{array}$ \\
\hline 93.33 & Move 7 & Obligatory \\
86.66 & Move 1 & \\
73.33 & Move 2 & \\
30 & Move 4 & Optional \\
20 & Move 5 & \\
13.33 & Move 6 & \\
6.66 & Move 3 & \\
\hline
\end{tabular}

As shown in table 4, Move 7, Move 1 and Move 2 respectively are the three most frequently found moves, each with percentage of occurrences above $60 \%$. Thus, Move 1 , Move 2 and Move 7 are considered 'obligatory' whereas Move 3, Move 4, Move 5 and Move 6 are considered optional because they occurred less than $60 \%$ in the thirty CEO messages in inflight magazines. The obligatory moves found in this study may represent the style of writing based on the communicative purposes of the studied Message from the $\mathrm{CEO}$ in in-flight magazines.

\subsection{Organizations of moves and steps}

Organizations of moves and steps suggest a prominent order of occurrences of moves and steps found in Messages from the CEO in in-flight magazines. Thus, apart from the frequencies of moves and steps, organizations of moves and steps found in the articles are also presented as follows:

Table 5. Organization of Moves and Steps in the thirty studied Message from the CEO in inflight magazines

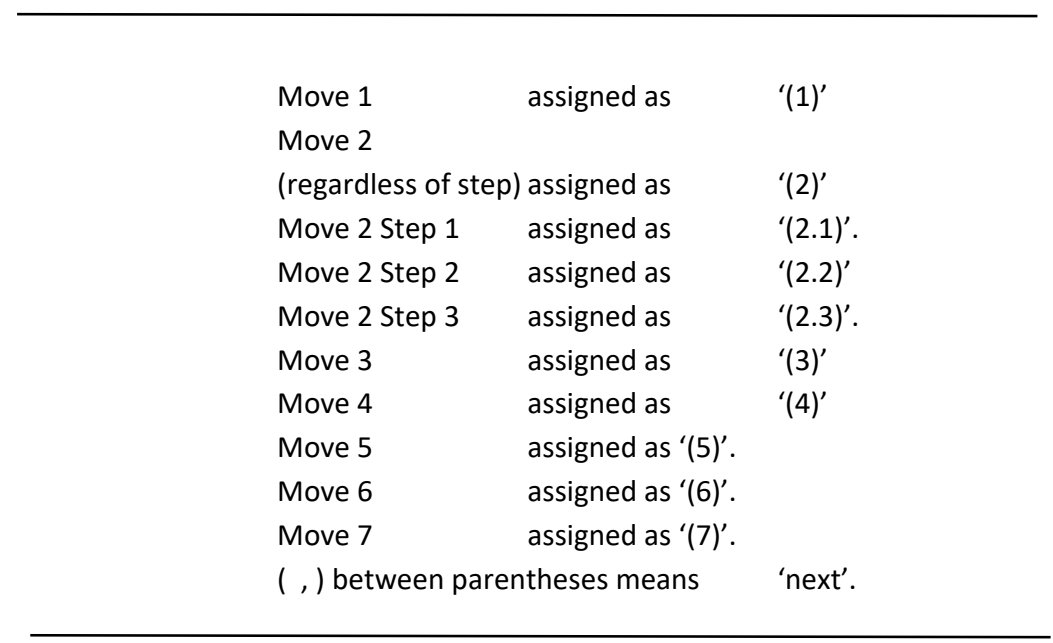


The most prominent organization of moves and steps in this study was (1), (2), and (7). That was, Move 1 was the most frequently found move at the beginning of Messages from the CEO in in-flight magazines. Next, in this study, Move 2 Step 1 always preceded the other steps of Move 2. In other words, Move 2, Step 2 and Move 2, Step 3 were always preceded by Move 2, Step 1.

Moreover, Step 1, Step 2 or Step 3 of Move 2, was found to be repetitive in every studied message from the CEO which contained Move 2. This means that there were usually more than one discoursal units found for Move 2.

Twenty-nine out of thirty messages from the $\mathrm{CEO}$ in in-flight magazines ended with Move 7; 96.66\%.

Move 3, Move 4, Move 5 and Move 6 were categorized as optional moves and their organizations did not show any predictable order of occurrence except for the fact that they never occurred at the beginning or the end of any studied texts.

\section{Discussion}

\subsection{Obligatory Moves}

- Obligatory Move 7 "Ending politely' is the most frequently found move at $93.33 \%$. This is conventional according to Bhatia's (2014) 'promotional genre', which is a form of written text in a professional setting. In the Message from the $\mathrm{CEO}$ in in-flight magazines studied, it is found that Move 7 occurred only at the end of the message.

- Obligatory Move 1 'Establishing credentials' is the second most frequently found move at $86.66 \%$. While Move 7 occurs only at the end of Message from the CEO in in-flight magazines, Move 1 is found mostly at the beginning of the messages. However, the distribution of occurrences of Move 1 can be found in any part of the studied Message from the CEO in in-flight magazines.

Move 1 found in this study varies in terms of topic. Move 1 may discuss the following; how the airline companies are involved in or contribute to environmental issues, special occasions or events, airline's achievements, etc. These topics can be any global, national, or cultural issues or events that the airline companies wish to communicate to their customers. Articles containing Move 1 agree with two of Thurlow and Jaworski's (2003) suggested dominant content categories in in-flight magazines. These two dominant content categories are 1) airline news and 2) business information. Move 1 not only contributes to being a dominant content category in in-flight magazines overall, but it is also an obligatory move in Message from the $\mathrm{CEO}$ in the thirty studied in-flight magazines.

- Obligatory Move 2 Predominantly, Move 2 Step 1, Step 2 and Step 3 are found to be repetitive in every CEO message which contains Move 2. For example, from the total of fifteen moves, the Message from the CEO (number 4) contains ten moves of Move 2 which consists of all three steps of the move. Another example is CEO message number 12 which consists of a total of nine moves consisting of seven moves of Move 2. This is equal to $78 \%$. Move 2 'Introduction of the offer' comprises 3 steps which are; 1) Offering the product or service, 2) Essential detailing of offer, and 3) Indicating value of the offer. 
Move 2 Step 1, 'Offering the product or service' is comparable to two of Rhodes' (1999) findings on the overall purpose of in-flight magazines, which are 1) providing passengers with a service and 2) promoting destinations covered by the carrier. The airline industry is a service business-oriented unit, thus it is in this industry's nature to offer service to customers. The major goal of airline business activity is to sell flight tickets, thus destinations are promoted to stimulate and serve customers' needs and wants.

The prominence of Move 2 also supports Thurlow and Jaworski's (2003) findings, which state that the most dominant content category is 'travel and destination information'. However, in Message from the CEO in in-flight magazines, the purpose of travel and destination information is to promote sales. In other words, the analysed messages from the CEO in in-flight magazines tend to persuade readers to buy the airlines' products and services by informing the audience of the products and services the airlines offer. Likewise, Boonchayaanant's (2003) findings suggest that informative and persuasive communicative purposes tend to be the main purposes of hotel brochures, which are another form of written text in the hospitality industry. Frequent occurrences of Move 2 assert the nature of the selected Message from CEO in this study of being a sales promotion letter.

The obligatory moves found in this study may represent the style of writing based on communicative purposes of the studied Message from the CEO in in-flight magazines.

\subsection{Optional moves}

While the three most frequently found moves are Move 7, 93.33\%, Move 1, 86.66\%, and Move 2, $73.33 \%$, the least occurring move is Move 3 'Offering incentives', which occurs only $6.66 \%$. This suggests that it is not conventional for Message from the $\mathrm{CEO}$ in in-flight magazines to offer incentives, which is unlike sales promotion letters (Bhatia, 2014). The other optional moves are Move 4 'Enclosing documents', 30\%, Move 5, 'Soliciting responses', $20 \%$, and Move 6 'Using pressure tactics' $13.33 \%$.

\subsection{Move and steps organizations}

The organisation of Move 7, followed by Move 1 and then Move 2 is predominant in the study. However, Move 3, Move 4, Move 5 and Move 6, are not obligatory. The predominant moves organisation found in this study

[( 7 ), ( 1 ), ( 2 )] appears to be conventional when compared to Bhatia's (2014) moves model for sales promotion letters, which also starts with Move 1 followed by Move 2 and ends with Move 7. In other words, messages from the $\mathrm{CEO}$ in in-flight magazines tend to establish credentials or restate an airline's position and trustworthiness before offering products and services and ending politely.

\section{Conclusion}

This study investigated only moves and steps in the thirty purposively selected messages from the CEO in five in-flight magazines. The findings from this study can only be generalised within the selected airlines only. As for the analysis, only moves, and steps and moves and their organisations were investigated based on Bhatia's (2014) model. The findings from this study could be an example and a guideline for in-flight magazines and related writings pedagogy for international communication. Considering moves and steps frequency of occurrences, it can be seen that Move 7, Move 1 and Move 2 respectively are the three most frequently found moves and categorised as obligatory' moves in this study whereas Move 3, 
Move 4, Move 5 and Move 6 are considered optional. Regarding moves and steps organisations, the most prominent organisation is Move 1 followed by Move 2 and Move 7. To write a message from $\mathrm{CEO}$ in in-flight magazine, the findings from this study suggest that at least three moves which are Move 1 'Establishing credentials', Move 2 'Introduction of the offer' and Move 7 'Ending politely' respectively should be included while the other moves are optional. This may lead to scepticism of whether the three obligatory moves could effectively serve the overall purpose of a sales promotion letter in the form of a message from CEO as recognised by its discoursal units of written text. Further studies are suggested in order to investigate the effectiveness of such mass communication along with the development of in-flight communication by airline companies which may change over time.

\section{Reference}

Arbitron (2006). The Arbitron In-Flight Media Study: Exploring Frequent Flyers' Engagement with Airline Magazines and In-

Flight Available October 10, 2010. (Online) http://www.arbitron.com/study/infli ght_media_study.asp

Bhatia, V. (2004). Worlds of written discourse: $A$ genre-based view, A\&C Black.

Bhatia, V. K. (2008). Creativity and accessibility in written professional discourse. World Englishes 27(3-4): 319-326.

Bhatia, V. K. (2014). Analysing genre: Language use in professional settings. Routledge.

Blue, G. M. and M. Harun (2003). Hospitality language as a professional skill. English for Specific Purposes 22(1): 73-91.

Boonchayaanant, V. (2003). A genre-based analysis of tourist leaflets produced and distributed in the United States of America.

Kachru, B. B. (1981). The pragmatics of nonnative varieties of English. English for cross-cultural communication (pp. 15-39).

Palgrave Macmillan UK.

Kanoksilapatham, B. (2005). Rhetorical structure of biochemistry research articles. English for Specific Purposes 24(3): 269-292.
Kanoksilapatham, B. (2007). Writing scientific research articles in Thai and English: Similarities and differences. Silpakorm University International Journal 7: 172203.

Quirk, R. (1985). The English language in a global context. English in the world: Teaching and learning the language and literatures, 16.

Rhodes, L. (1999). Inflight magazines: Changing how travelers read. Journal of Magazine and New Media Research 1(2).

Roberts, J. (1993). Marketing for the hospitality industry, Hodder \& Stoughton.

Swales, J. (1990). Genre analysis: English in academic and research settings, Cambridge University Press.

Thanasupsin, K., Chaichana, S., \& Pliankarom, S. (2010). Factors influencing mode selections of low-cost carriers and a

full-service airline in Thailand. Transportation Journal, 35-47.

Thurlow, C. and A. Jaworski (2003). Communicating a global reach: Inflight magazines as a globalizing genre in tourism. Journal of Sociolinguistics 7(4): 579-606. 